\title{
Exigências nutricionais de zinco para frangos de corte machos e fêmeas na fase inicial
}

\author{
Paulo Cezar Gomes ${ }^{1}$, Dalton César Milagres Rigueira ${ }^{2}$, Horacio Santiago Rostagno ${ }^{1}$, Luiz \\ Fernando Teixeira Albino ${ }^{1}$, Gladstone Brumano ${ }^{2}$, Marlene Schmidt ${ }^{2}$
}

\footnotetext{
${ }^{1}$ Departamento de Zootecnia da Universidade Federal de Viçosa, Viçosa - MG. Bolsista do CNPq

2 Programa de Pós-graduação - Universidade Federal de Viçosa , Viçosa - MG.
}

\begin{abstract}
RESUMO - Com o objetivo de determinar as exigências nutricionais de zinco para frangos de corte machos e fêmeas na fase inicial (8 a 21 dias), foram utilizadas 384 aves, metade fêmea e metade macho para cada experimento. Foi formulada uma dieta basal atendendo às exigências nutricionais das aves, com exceção do nível de Zn, que permaneceu deficiente no nível de $12 \mathrm{ppm}$. Os tratamentos consistiram da suplementação de $\mathrm{Zn}$ à dieta basal com óxido de zinco nos níveis de 12,0; 37,0; 62,0; 87,0; 112,0 e 137,0 ppm de Zn. As características avaliadas foram: ganho de peso, consumo de ração, conversão alimentar e concentração de Zn no osso, no fígado e no soro. Não houve efeito dos níveis de Zn sobre as características de desempenho e a concentração de Zn no fígado das aves. Houve efeito dos níveis de Zn sobre as concentrações de Zn no soro e no osso. Verificou-se interação entre níveis de zinco e sexo somente para concentração de Zn no osso. As exigências estimadas foram de 86,12 ppm para frangos de corte machos e de 85,70 ppm para fêmeas. Para a concentração de Zn no soro, a exigência estimada foi de 113,55 ppm, entretanto, considerando a importância desse mineral no desenvolvimento ósseo, a exigência de Zn é de 86,12 ppm para frangos de corte machos e de 85,70 ppm para fêmeas de 8 a 21 dias de idade.
\end{abstract}

Palavras-chave: exigência, fígado, mineral, osso, soro

\section{Zinc requirements for male and female broilers in the initial phase}

\begin{abstract}
Three hundred and eighty four broilers chicks, half males and half females, were used to determine the zinc requirement for broilers in the initial phase (from 8 to 21 days). A basal diet was formulated that meet the nutritional requirements, except for $\mathrm{Zn}$ level, which was kept deficient at $12.00 \mathrm{ppm}$. The treatments consisted of $\mathrm{Zn}$ supplementation to the basal diet with Zn oxide, in the levels of 12.0, 37.0, 62.0, 87.0, 112.0 and $137.0 \mathrm{ppm}$ of Zn. The characteristics evaluated were weight gain, feed intake, feed:gain ratio and $\mathrm{Zn}$ concentration in the bone, liver and blood serum. There was no effect of $\mathrm{Zn}$ levels on performance characteristics and on $\mathrm{Zn}$ concentration in liver of birds. There was effect of $\mathrm{Zn}$ levels on $\mathrm{Zn}$ concentration in serum and bone. Significant interaction between $\mathrm{Zn}$ levels and sex was observed only for $\mathrm{Zn}$ concentration in bone. The requirement estimations were $86.12 \mathrm{ppm}$ and $85.70 \mathrm{ppm}$ for broilers males and females, respectively, from 8 to 21 days of age. Based on the Zn concentration in the serum, requirement estimated was of 113.55 ppm, however, considering the importance of this mineral in the bone development, requirement of $\mathrm{Zn}$ is of $86.12 \mathrm{ppm}$ and $85.70 \mathrm{ppm}$ for male and female broilers from 8 to 21 days of age.
\end{abstract}

Key Words: bone, liver, mineral, requirement, serum

\section{Introdução}

A suplementação de microminerais em dietas para aves freqüentemente é feita em quantidades superiores às exigências como forma de assegurar o bom desempenho das aves. Geralmente, essa prática está relacionada ao desconhecimento do nutricionista quanto à real exigência das aves. Os microminerais são essenciais para a atividade fisiológica dos animais, ainda que em pequenas concentra- ções na dieta e, normalmente, suas exigências são determinadas usando dietas purificadas, o que pode não refletir a real necessidade dos animais. Ressalta-se que deficiência ou excesso de um mineral específico é diagnosticado com moderada dificuldade em pesquisas controladas e com muita dificuldade em condições de campo (Miller, 1984), o que dificulta o trabalho do nutricionista.

De modo geral, a suplementação de microminerais aos animais é feita utilizando formas salinas inorgânicas simples 
com biodisponibilidades diferentes, o que explica o fato de suplementos minerais com os mesmos níveis nutricionais promoverem resultados de desempenho diferentes.

O zinco é importante na síntese, no armazenamento e na secreção de hormônios. É um dos constituintes da metaloenzima anidrase carbônica e atua no equilíbrio ácidobase do organismo e na calcificação óssea (Leeson \& Summers, 2001). Os tecidos muscular e ósseo são as principais reservas de zinco e possuem capacidade de liberar possíveis excedentes em condições de deficiência na dieta (Underwood, 1999). Portanto, esse mineral está diretamente associados ao crescimento e ao desenvolvimento do tecido ósseo. Outras funções atribuídas ao zinco são proteção de membranas, efeito antioxidante que protege os grupos sulfidrilas nas membranas, metabolismo de prostaglandinas e metabolismo de lipídeos.

De modo geral, a literatura sobre a suplementação mineral das aves é escassa e, muitas vezes, baseada em conceitos obtidos em pesquisas realizadas nas décadas de 50 e 60. Atualmente, os frangos possuem composição corporal diferenciada, além das possíveis diferenças entre os sexos nas exigências nutricionais, que não têm sido considerados nas tabelas. O NRC (1994) e Rostagno et al. (2000) recomendam, respectivamente, 40 e 60 ppm de zinco para frangos de corte, tanto machos como fêmeas. Portanto, são necessárias maiores informações acerca da real exigência de zinco das aves. Neste estudo, objetivou-se determinar a exigência de zinco para frangos de corte machos e fêmeas na fase inicial.

\section{Material e Métodos}

O experimento foi realizado no Setor de Avicultura do Departamento de Zootecnia da Universidade Federal de Viçosa, UFV, Minas Gerais. Foram utilizados 384 pintos de corte de 7 dias de idade, linhagem Avian Farms (192 machos e 192 fêmeas), distribuídos em 48 boxes de uma bateria metálica pintada com tinta automotiva, durante o período de 8 a 21 dias de idade. Até o sétimo dia de vida, as aves foram alimentadas com dieta para atender todas as exigências nutricionais.

Adotou-se um esquema fatorial $6 \times 2$, composto de seis níveis de Zn e dois sexos, em delineamento inteiramente casualizado com quatro repetições e oito aves por unidade experimental.

As aves foram criadas de acordo com as recomendações de manejo descritas por Gomes et al. (1996), com programa de luz contínuo, com 24 horas de luz (natural + artificial) durante todo o período experimental.
A composição química dos ingredientes da dieta experimental e da água fornecida às aves (antes e durante a fase experimental) foi determinada no Laboratório de Nutrição Animal do Departamento de Zootecnia da Universidade Federal de Viçosa, conforme metodologia descrita por Silva \& Queiroz (2002). O óxido de zinco (ZnO) utilizado continha $73,0 \%$ de zinco. Amostras de água foram coletadas antes e durante a fase experimental para análises, no entanto, os resultados apontaram somente traços do mineral em estudo (0,001 ppm).

A dieta basal foi formulada para atender às exigências nutricionais das aves, segundo recomendações de Rostagno et al. (2000), exceto para Zn, que permaneceu deficiente no nível de 12,00ppm (Tabela 1). Para a suplementação de Zn à dieta basal, utilizou-se o óxido de zinco comercial visando atingir os seguintes níveis: 0,0; 25,0; 50,0; 75,0; 100,0 e 125,0 ppm, resultando em um total de $12.0 ; 37,0 ; 62,0 ; 87,0 ; 112,0$; e 137,0 ppm de zinco, respectivamente, na dieta.

As aves receberam ração e água à vontade e foram pesadas no início e ao final do experimento para avaliação do ganho de peso, do consumo de ração e da conversão alimentar. Ao final do experimento, 192 aves com o peso médio do boxe (4 aves/boxe) foram amostradas para a coleta de sangue. Posteriormente, estas mesmas aves foram abatidas para retirada do fígado e da tíbia, para análises da concentração de Zn.

As tíbias (com as cartilagens adjacentes e livres de tecido muscular) e os fígados foram mantidos em estufa de ventilação forçada $\left(65^{\circ} \mathrm{C}\right)$ por 72 horas, desengordurados em extrator Soxhlet por 8 horas e triturados em moinhos de aço inoxidável. Em seguida, foram pesados em balança analítica e analisados quanto à concentração de $\mathrm{Zn}$, de acordo a metodologia descrita por Silva \& Queiroz (2002), em espectrofotômetro de absorção atômica, modelo 908, marca GBC, no laboratório de Nutrição Animal do Departamento de Zootecnia da Universidade Federal de Viçosa.

A fim de garantir que as aves apresentassem ao abate mesmo perfil metabólico de zinco no sangue, as aves foram mantidas em jejum por 1 hora, seguida de 1 hora de alimentação normal, viando fornecer alimento ao mesmo tempo às aves para que todas enchessem o papo. Em seguida, iniciou-se a retirada dos comedouros das gaiolas com intervalo de 5 minutos entre cada gaiola. Quando o comedouro da última gaiola foi retirado, iniciou-se o abate, na mesma seqüência de retirada dos comedouros e no mesmo intervalo de tempo citado. O sangue foi coletado e dessorado naturalmente. O soro foi transferido para vidrarias adequadas e submetido à análise da concentração de zinco de acordo com a metodologia descrita por Silva \& Queiroz 
Tabela 1 - Composição da dieta basal

\begin{tabular}{|c|c|}
\hline Ingrediente & $\%$ \\
\hline Açúcar & 5,000 \\
\hline Farelo de soja & 10,220 \\
\hline Farelo de glúten milho & 10,000 \\
\hline Farinha de milho & 45,010 \\
\hline Milho & 13,343 \\
\hline Óleo vegetal & 1,080 \\
\hline Calcário & 1,050 \\
\hline Fosfato bicálcico & 2,040 \\
\hline Proteína isolada de soja & 10,000 \\
\hline Sal & 0,510 \\
\hline Mistura vitamínica ${ }^{1}$ & 0,100 \\
\hline Mistura mineral $^{2}$ & 0,100 \\
\hline Antioxidante BHT & 0,010 \\
\hline Anticoccidiano $^{3}$ & 0,050 \\
\hline Promotor de crescimento ${ }^{4}$ & 0,002 \\
\hline DL-Met 99\% & 0,280 \\
\hline Lys $\mathrm{HCl}, 78 \%$ & 0,560 \\
\hline L-Thr, 98\% & 0,090 \\
\hline L-Trp, 98\% & 0,015 \\
\hline Cloreto de colina, $60 \%$ & 0,040 \\
\hline Areia lavada & 0,500 \\
\hline \multicolumn{2}{|c|}{ Composição nutricional calculada } \\
\hline PB (\%) & 21,800 \\
\hline EM (kcal/kg) & 3.000 \\
\hline FB (\%) & 1,169 \\
\hline Ácido linoléico (\%) & 1,091 \\
\hline Са (\%) & 0,960 \\
\hline $\mathrm{P}$ disponível (\%) & 0,450 \\
\hline $\mathrm{Na}(\%)$ & 0,222 \\
\hline $\mathrm{Zn}(\mathrm{mg} / \mathrm{kg})$ & 12,000 \\
\hline Lys total (\%) & 1,263 \\
\hline Met total (\%) & 0,604 \\
\hline Met + Cys (\%) & 0,897 \\
\hline Thr (\%) & 0,795 \\
\hline $\operatorname{Trp}(\%)$ & 0,207 \\
\hline \multicolumn{2}{|c|}{ 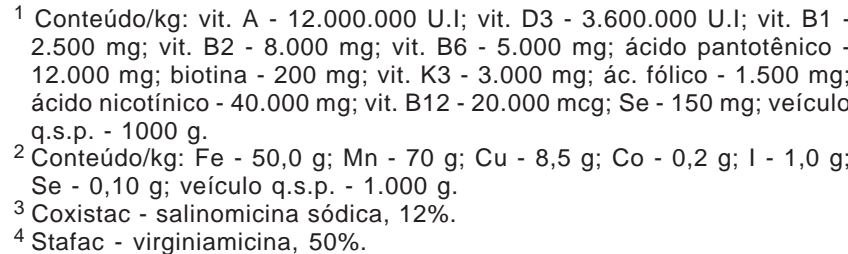 } \\
\hline
\end{tabular}

(2002) em espectrofotômetro de absorção atômica, modelo 908, marca GBC.

As análises estatísticas dos parâmetros avaliados neste experimento foram realizadas de acordo com o programa SAEG - Sistema para Análises Estatísticas e Genéticas (UFV, 2001) e as estimativas de exigências de zinco foram feitas utilizando-se o modelo de regressão quadrática.

\section{Resultados e Discussão}

As incidências de anormalidades de pernas e dedos foram raras e aleatórias e, portanto, não podem ser atribuídas a efeitos de tratamento. Estes resultados diferem dos obtidos por McDowell (1992) e de Starcher et al. (1980), que observaram má formação dos ossos longos de forma proporcional ao grau de deficiência de zinco da dieta.

Não houve efeito significativo dos níveis de zinco $(\mathrm{P}>0,05)$ sobre o ganho de peso, o consumo de ração e a conversão alimentar das aves (Tabela 2). Esses resultados foram semelhantes aos descritos por Leeson \& Summers (1982), que testaram cinco níveis de zinco (50, 100, 200, 400 e $800 \mathrm{ppm}$ ) em dietas para frangos de corte e verificaram que, aos 21 dias de idade, não houve efeito significativo das dietas sobre a taxa de crescimento e a conversão alimentar.

O sexo das aves não influenciou $(\mathrm{P}>0,01)$ o consumo de ração, o ganho de peso e a conversão alimentar. Do mesmo modo, não houve interação sexo $\times$ níveis de zinco $(P>0,05)$, comprovando que estes fatores agem de forma independente sobre as características de desempenho.

Houve efeito quadrático $(\mathrm{P}<0,01)$ dos níveis de zinco em relação à concentração de zinco no osso e no soro (Tabela 3). Da mesma forma, Teixeira et al. (1995), trabalhando com frangos de corte até os 21 dias de idade com dietas à base de milho e farelo de soja suplementadas com cinco níveis de zinco (0; 30; 60; 90 e 120 ppm), encontraram efeito quadrático somente para deposição de zinco nas tíbias e definiram a exigência de zinco suplementar (44 ppm)com base neste parâmetro. Segundo McDowell (1992), as reservas prontamente disponíveis são pequenas e uma mudança para uma dieta com níveis baixos de zinco

Tabela 2 - Desempenho de frangos de corte machos e fêmeas de 8 a 21 dias de idade alimentados com rações contendo diferentes níveis de zinco $(\mathrm{Zn})$

\begin{tabular}{lcccc}
\hline $\begin{array}{l}\text { Nível de } \\
\text { Zn (ppm) }\end{array}$ & Sexo & $\begin{array}{c}\text { Ganho de } \\
\text { peso (g) }\end{array}$ & $\begin{array}{c}\text { Consumo } \\
\text { de ração (g) }\end{array}$ & $\begin{array}{c}\text { Conversão } \\
\text { alimentar (g:g) }\end{array}$ \\
\hline 12,0 & M & 570,0 & 805,2 & 1,41 \\
37,0 & M & 545,0 & 762,3 & 1,40 \\
62,0 & M & 547,0 & 768,9 & 1,40 \\
87,0 & M & 543,0 & 768,2 & 1,42 \\
112,0 & M & 540,0 & 774,5 & 1,43 \\
137,0 & M & 563,0 & 749,2 & 1,33 \\
\hline Média & & 551,33 & 771,38 & 1,39 \\
\hline 12,0 & $\mathrm{~F}$ & 571,0 & 785,0 & 1,38 \\
37,0 & $\mathrm{~F}$ & 556,0 & 764,7 & 1,38 \\
62,0 & $\mathrm{~F}$ & 532,0 & 743,0 & 1,40 \\
87,0 & $\mathrm{~F}$ & 555,0 & 759,3 & 1,34 \\
112,0 & $\mathrm{~F}$ & 559,0 & 777,4 & 1,39 \\
137,0 & $\mathrm{~F}$ & 565,0 & 793,9 & 1,40 \\
\hline Média & & 556,33 & 770,5 & 1,38 \\
\hline Nível de Zn & & $\mathrm{ns}$ & $\mathrm{ns}$ & $\mathrm{ns}$ \\
Sexo & & $\mathrm{ns}$ & $\mathrm{ns}$ & $\mathrm{ns}$ \\
Sexo $\times$ Zn & & $\mathrm{ns}$ & $\mathrm{ns}$ & $\mathrm{ns}$ \\
\hline CV (\%) & & 5,30 & 6,20 & 6,10 \\
\hline
\end{tabular}

ns - não-significativo $(P>0,05)$ pelo teste $F ; M=$ macho; $F$ = fêmea. 
Tabela 3 - Concentração de zinco no osso, no fígado e no soro de frangos de corte machos e fêmeas de 8 a 21 dias de idade alimentados com rações formuladas com diferentes níveis de zinco

\begin{tabular}{lcccc}
\hline $\begin{array}{l}\text { Nível de } \\
\text { Zn (ppm) }\end{array}$ & Sexo & ZnO (ppm) & ZnF (ppm) & ZnS (ppm) \\
\hline 12,0 & M & 99,71 & 61,70 & 1,62 \\
37,0 & $\mathrm{M}$ & 145,80 & 60,00 & 1,84 \\
62,0 & $\mathrm{M}$ & 178,72 & 59,48 & 1,96 \\
87,0 & $\mathrm{M}$ & 159,64 & 57,40 & 1,99 \\
112,0 & $\mathrm{M}$ & 165,70 & 56,70 & 2,53 \\
137,0 & $\mathrm{M}$ & 143,65 & 56,86 & 2,03 \\
\hline Média & & 148,87 & 58,69 & 1,99 \\
\hline 12,0 & $\mathrm{~F}$ & 103,37 & 55,74 & 153 \\
37,0 & $\mathrm{~F}$ & 168,15 & 56,71 & 1,97 \\
62,0 & $\mathrm{~F}$ & 154,76 & 62,08 & 1,91 \\
87,0 & $\mathrm{~F}$ & 176,64 & 58,71 & 2,06 \\
112,0 & $\mathrm{~F}$ & 153,68 & 62,66 & 2,28 \\
137,0 & $\mathrm{~F}$ & 150,20 & 54,94 & 2,06 \\
\hline Média & & 151,13 & 58,47 & 1,97 \\
\hline Níveis de Zn & $1 * *$ & $\mathrm{~ns}$ & $1 * *$ \\
Sexo & & $*$ & $\mathrm{~ns}$ & $\mathrm{~ns}$ \\
Sexo $\times$ Zn & & $* *$ & $\mathrm{~ns}$ & $\mathrm{~ns}$ \\
\hline CV (\%) & & 2,40 & 9,90 & 16,7 \\
\hline ZnO Zncon & & &
\end{tabular}

$\mathrm{ZnO}=$ zinco no osso; $\mathrm{ZnF}=$ zinco no fígado; $\mathrm{ZnS}=$ zinco no soro; $\mathrm{M}=$ macho; $\mathrm{F}=$ fêmea.

** $(P<0,01)$; * $(P>0,05)$ pelo teste $F$

1 Efeito quadrático.

ns - não-significativo $(P>0,05)$ pelo teste $F$. provoca decréscimo na concentração de zinco no soro em um período máximo de 24 horas.

A concentração de $\mathrm{Zn}$ no osso foi influenciada pelo sexo das aves, uma vez que as fêmeas tiveram $1,52 \%$ a mais de zinco no osso que os machos $(\mathrm{P}<0,05)$. Houve interação sexo $\times$ nível de zinco $(\mathrm{P}<0,01)$ para a concentração de zinco no osso. O desdobramento da interação comprovou que este fator atua de forma dependente sobre este parâmetro (sexo).

As exigências em zinco determinadas pela concentração de zinco no osso foram de 86,12 ppm para os machos e de 85,70 ppm para as fêmeas (Tabela 4).

No soro, como não houve interação $(P>0,05)$ sexo $\times$ nível de zinco, o valor da exigência de zinco para ambos os sexos foi de 113,55 ppm. Segundo Lowe et al. (1991), o nível de zinco no soro sangüíneo é freqüentemente utilizado para avaliar o status de zinco do organismo, mas estados de estresse podem provocar redução na concentração de zinco do soro, não associada à deficiência de zinco na dieta, portanto, este não é um bom parâmetro para medir a exigência de zinco, uma vez que não é influenciado apenas pelo aporte da dieta.

A tíbia de aves tem sido amplamente usada em experimentos para determinar as exigências nutricionais e a

Tabela 4 - Sumário das análises de determinação das exigências de zinco estimadas pelo modelo quadrático para frangos de corte de 8 a 21 dias de idade alimentados com rações formuladas com diferentes níveis de zinco

\begin{tabular}{|c|c|c|c|c|}
\hline Item & Equação ajustada & Exigência & $\mathrm{R}^{2}$ & SQD \\
\hline $\mathrm{ZnO}$ (macho) (ppm) & $\hat{\mathrm{Y}}=78,98+2,2055 * \mathrm{~N}-0,012805 * \mathrm{~N}^{2}$ & 86,12 & 0,90 & 384,8 \\
\hline ZnO (fêmea) (ppm) & $\hat{\mathrm{Y}}=92,60+1,8591 * \mathrm{~N}-0,010846 * \mathrm{~N}^{2}$ & 85,70 & 0,73 & 880,7 \\
\hline ZnS (ppm) & $\hat{\mathrm{Y}}=1,4322+0,0131 * \mathrm{~N}-0,00005764 * \mathrm{~N}^{2}$ & 113,55 & 0,71 & 0,22 \\
\hline
\end{tabular}

$\mathrm{ZnO}=$ zinco no osso; $\mathrm{ZnS}=$ zinco no soro.

SQD - soma de quadrado dos desvios.

biodisponibilidade de minerais de fontes orgânicas (Fialho, 1991) e inorgânicas (Ledoux et al., 1989; Wedekind \& Baker, 1990; Ledoux et al., 1991; Nobre et al., 1993). Considerando a importância do zinco no desenvolvimento ósseo, a concentração de zinco no osso (tíbia) utilizada para estimar a exigência desse mineral é viável, embora vários autores (Rostagno et al., 2000; Gomes et al., 1996) tenham percebido que a exigência para maximizar parâmetros ósseos é maior que para otimizar valores de desempenho.

A deposição de minerais na tíbia como resposta à suplementação na dieta é um parâmetro bastante utilizado e sua sensibilidade tem superado a de avaliações feitas em outros órgãos e tecidos, como fígado, rins, pâncreas e sangue (Fialho, 1991; Bertechini et al., 1992 a; Nobre et al., 1993).
Os valores de exigências de zinco para frangos de corte de 8 a 21 dias de idade, considerando a variável zinco no osso, foram: 86,12 ppm para os machos e 85,70 ppm para as fêmeas. As exigências de zinco encontradas neste trabalho foram superiores às citados por Rostagno et al. (2000), que recomendaram níveis de 60 ppm para frangos de corte nas diferentes fases de criação. Foram superiores ainda às descritas pelo NRC (1994), que recomendou níveis de 40 ppm, e por Bertechini et al. (1992), que estimaram em 60 ppm a exigência de zinco para frangos de corte. Vários autores (Rostagno et al., 2000; Gomes et al., 1996) têm demonstrado que os valores de exigência, principalmente minerais, quando estimados pelas variáveis de osso, são superestimados em relação àqueles estimados pelas caracte- 
rísticas de desempenho, o que pode explicar os maiores valores de exigência de zinco encontrados neste trabalho.

\section{Conclusões}

De acordo com os resultados obtidos neste estudo, a exigência de zinco para frangos de corte de 8 a 21 dias de idade, utilizando-se como referência a variável zinco no osso, é de 86,12 ppm para machos e de 65,70 ppm para fêmeas.

\section{Literatura Citada}

BERTECHINI, A.G.; HOSSAIN, S.M.; NOBRE, P.T. Efeito de vários níveis de zinco no desempenho e composição mineral do tecido em frangos de corte. In: REUNIÃO ANUAL DA SOCIEDADE BRASILEIRA DE ZOOTECNIA, 29., 1992, Lavras. Anais... Sociedade Brasileira de Zootecnia, 1992. p.324.

FIALHO, F.B. Técnica de slope ratio na determinação de biodisponibilidade de nutrientes. Porto Alegre: Universidade Federal do Rio Grande do Sul, 1991. 155p.

GOMES, P.C.; ALBINO, L.F.T.; SILVA, M.A. Criação de frangos de corte. Viçosa, MG: Universidade Federal de Viçosa, 1996. (Informe Técnico, 78).

LEESON, S.; SUMMERS, J.D. Effect of high dietary levels of supplemental zinc, manganese, copper or iron on broiler performance to three weeks of age and accumulation of these minerals in tissue and excreta. Nutrition Reports International, v.25, p.591-599, 1982.

LEESON, S.; SUMMERS, J.D. Nutrition of the chickens. 4.ed. Guelph: University Books, 2001. p.591.

LEDOUX, D.R.; HENRY, P.R.; AMMERMAN, C.B. et al. Effect of dietary copper on tissue mineral composition as an estimate of copper bioavaibility in broiler chicks. Nutrition Reports International, v.39, p.1117-1126, 1989.

LEDOUX, D.R.; HENRY, P.R.; AMMERMAN, C.B. et al. Estimation of the relative bioavailibility of inorganic copper sources for chicks using tissue uptake of copper. Journal of Animal Science, v.69, p.215-222, 1991.

LOWE, N.M.; BREMER, I.; JACKSON, M.J. Plasma 65 Zn kinetics in the rat. British Journal of Nutrition, v.65, p.445-455, 1991.

McDOWELL, L.R. Minerals in animal and human nutrition. San Diego: Academy Press, 1992. 524p.

MILLER, W.J. Proper mineral balance improves livestock performance. Feedstuffs, v.56, p.27-32, 1984.

NOBRE, P.T.C.; HOSSAIN, S.M.; VALE, R.A. Biodisponibilidade do carbonato e óxido de zinco para frangos de corte. In: CONFERÊNCIA DA APINCO DE CIÊNCIA E TECNOLOGIA AVÍCOLA, 1993, Santos. Anais... Santos: Fundação APINCO de Ciência e Tecnologia Avícolas, 1993. p.28.

ROSTAGNO, H.S.; ALBINO, L.F.T.; DONZELE, J.L. et al. Composição de alimentos e exigências nutricionais de aves e suínos: tabelas brasileiras. Viçosa, MG: Editora UFV, 2000.

SILVA, D.J.; QUEIROZ, A.C. Análise de alimentos (métodos químicos e biológicos). Viçosa, MG: Editora UFV, 2002. 235p.

TARCHER, B.C.; GLAUBER, J.G.; MADARAS, J.G. Zinc absorption and its relationship to intestinal metallothionein. Journal of Nutrition, v.110, p.1391-1397, 1980.

TEIXEIRA, A.S.; LOPEZ, J.; RUTZ, F. et al. Exigências nutricionais de zinco para pintos de corte. In: REUNIAO ANUAL DA SOCIEDADE BRASILEIRA DE ZOOTECNIA, 32., 1995, Brasília. Anais... Sociedade Brasileira de Zootecnia, 1995. p.561-563.

UNDERWOOD, E.J. The mineral nutrition of livestock. 3.ed. Wallingford: CABI, 1999. 614p.

UNIVERSIDADE FEDERAL DE VIÇOSA - UFV. SAEG - Sistema para análise estatística e genética, versão 8.0, Viçosa, MG: Fundação Arthur Bernardes, 2001. 150p.

WEDEKIND, K.J.; BAKER, D.H. Zinc bioavailibility in feedgrade sources of zinc. Journal of Animal Science, v.68, p.684-689, 1990. 